\title{
Theism and Contrastive Explanation
}

(Forthcoming in European Journal for the Philosophy of Religion, 9 [3] 2017)

\section{Daniel Came}

\begin{abstract}
I argue that there could not be grounds on which to introduce God into our ontology. My argument presupposes two doctrines. First, we should allow into our ontology only what figures in the best explanation of an event or fact. Second, explanation is contrastive by nature, in that the explanandum always consists in a contrast between a fact and a foil. I argue that God could not figure in true contrastive explanatory statements, because the omnipotence of God guarantees that for any true proposition $p$, God could have made it the case that $\sim p$ just as much as He could have made it the case that $p$.
\end{abstract}

\section{I}

I argue that there could not be grounds on which to introduce God into our ontology. My argument presupposes two doctrines:

A1: We should allow into our ontology only what figures in the best explanation of an event or fact.

A2: Explanation is contrastive by nature, in that the explanandum always consists in a contrast between a fact and a foil.

I argue that God could not figure in true contrastive explanatory statements, because the omnipotence of God guarantees that for any true proposition $p$, God 
could have made it the case that $\sim p$ just as much as He could have made it the case that $p$. I make three further assumptions:

A3: To be God, a being must be omnipotent.

A4: For any proposition $p$, an omnipotent being has the power to make $p$ true.

A5: Citing a cause is always explanatory.

A3 is accepted by most philosophers of religion, though a few (e.g., James Keller) reject it.

$\mathrm{A}_{4}$ is rejected by most philosophers of religion. For example, propositions like ' $2+2=4$ ' and ' $2+2=5$ ' seem to be examples of propositions that cannot be made true even by an omnipotent being. Therefore, I shall restrict $\mathrm{A}_{4}$ to contingent propositions. That is, omnipotence entails the power to make true, at most, all contingent propositions. Indeed, this is true on the best available current theories of omnipotence. ${ }^{1}$

$\mathrm{A}_{5}$, unlike $\mathrm{A}_{1}-\mathrm{A}_{4}$, is not essential to the paper's main argument. Instead, I use it in order to answer an objection without making a commitment to the thesis that all explanation is causal. ${ }^{2}$

\footnotetext{
${ }^{1}$ Further issues are raised by propositions that are true due to an act of free will. God cannot make such propositions true if there is genuine libertarian freedom. Similarly, propositions about the past: although it is contingent that Germany lost World War II, God cannot now make this false. I shall not pursue these complications here.

${ }^{2}$ A possible counterexample to $A_{5}$ is presented by chance events: in the case of chance events (e.g., a car hits my aunt) we can have a cause (the car with its velocity and the position of Aunty), but we do not have an explanation (at least not one "of the right kind"). I owe this point to Benedikt Göcke.
} 
Since Quine, the following ontological principle has seen much popularity: we should accept as existing only those entities which are postulated in the best explanation of what we accept to be the case. It follows that we have good reason to believe that $x$ exists only if $x$ has some some explanatory power: only those entities the postulation of which is necessary for explaining something should be believed to exist. ${ }^{3}$ I will argue that appeal to God is always explanatorily impotent.

For us to be justified in accepting the existence of God, the postulation of God must have some explanatory significance. A common argument for the nonexistence of God is that there is nothing the (best) explanation of which requires the postulation of God. This was Laplace's line when he told Napoleon that he did not believe in God because he had 'no need for that hypothesis.'

It has often been assumed that a canonical explanandum consists of a single event or fact. More recently, however, Peter Lipton has claimed that a canonical explanandum is a 'contrastive phenomenon': a pair consisting in a fact and a foil. ${ }^{5}$ A fully specified explanatory statement does not take the form ' $p$ explains why $q$ ',

\footnotetext{
3 "Only if" rather than "if and only if" because the latter would entail that we have eo ipso good reasons to believe that any $x$ with explanatory power exists, which is absurd.

${ }^{4}$ Strictly speaking, Laplace was here concerned with whether one needs God as a hypothesis in natural science, not whether we need God in other contexts. This is also the vein of Russell's 'teapot atheism': there is no more evidence for the existence of God - no more explananda calling out for the postulation of God - than there is for the existence of a miniature China teapot orbiting the sun. See Bertrand Russell, 'Is There a God?' in The Collected Papers of Bertrand Russell, Volume 11: Last Philosophical Testament, ed. J. G. Slater and P. Köllner, (London: Routledge, 1997). ${ }^{5}$ Peter Lipton, 'Contrastive Explanation' in D. Knowles (ed.), Explanation and its Limits, (Cambridge: Cambridge University Press, 1990).
} 
but rather the form ' $p$ explains why $q$ rather than $r{ }^{6}{ }^{6}$ In its minimal form, an explanatory statement would be ' $p$ explains why $q$ rather than $\sim q$ '.

Let us further assume that one way to explain something (e.g., a contrastive phenomenon) is by citing its cause - what brought it about or made it the case. The assumption is that causal explanation is a genuine and legitimate kind of explanation. This is much weaker than holding a causal account of explanation, according to which all or most explanation is causal. ${ }^{7}$ The claim is merely that citing of a cause is explanatory.

Some contrastive explanatory statements are therefore causal statements. They are statements of the form ' $p$ caused $q$ rather than $r$ ', or at least ' $p$ caused $q$ rather than $\sim q$ ', Such a statement may be ambiguous as between ' $p$ caused $q$ rather than causing $r$ ' and ' $p$ caused $q$-rather-than-r'. That is, there is an ambiguity between a contrast of causation and a causation of contrast. But this ambiguity will not matter for present purposes.

Many theists will reject this approach to explanation in favour of (say) the deductive-nomological or holistic models of explanation. Hence I shall now say a few words on why this approach to explanation is good on independent grounds.

The central thesis of the contrastive approach to explanation is that requests for an explanation are explicitly or implicitly contrastive. They have the

\footnotetext{
${ }^{6}$ Lipton's favourite example is the following. Lipton's three-year old son throws the food on the floor. When asked to explain his misdeed, the child says that he was not hungry anymore. This explains why the child threw the food on the floor rather than eat it, but it does not explain why he threw the food on the floor rather than leave it in his plate.

${ }^{7}$ David Lewis, 'Causal Explanation' in his Philosophical Papers, Volume 2, (Oxford: Oxford

University Press, 1986).
} 
form 'Why $p$ rather than $q$ ?', rather than simply 'Why $p$ ?'. When the contrast remains implicit, it is obvious in the context in which the question is posed. Moreover, what counts as an explanatory cause depends not just on fact $p$ but also on the foil $q$. Thus 'the increase in temperature might be a good explanation of why the mercury in a thermometer rose rather than fell, but not a good explanation of why it rose rather than breaking the glass' (Lipton 2001: 48). Not all of $p$ 's causes explain $p$ in a given context; the foil in a contrastive question partially determines which causes are explanatory and which are not. A good explanation requires a cause that made the difference between the fact and foil. Thus the fact that 'Smith had syphilis may explain why he rather than Jones contracted paresis (a form of partial paralysis), if Jones did not have syphilis; but it will not explain why Smith rather than Doe contracted paresis, if Doe also had syphilis' (Lipton 2001: 49). Contrastive explanations bring out the way in which what makes a difference between $p$ 's occurring or not depends on what we mean by $p$ not occurring, on our choice of foil. In so doing, it seems also to support the idea that the reason (some) causes are explanatory is that they identify what made the salient difference between the occurrence and non-occurrence of the effect of interest. Theories of explanation (such as the deductive-nomological or holistic models) which leave the contrastive structure of explanation unspecified are therefore greatly incomplete models of explanation.

We are now in a position to see why appeal to God is always explanatorily impotent. Because, by $\mathrm{A}_{3}$, God is omnipotent, there is no possible fact, event, or 
state of affairs He would be unable to bring about. And by $\mathrm{A}_{4}$, there is no contingent proposition He could not make true. Moreover, His infinite power implies that differences in the effort required on God's part to bring about different states of affairs are negligible. It follows that for any true contingent proposition $p$, 'God caused p' (Or 'God caused it to be the case that $p$ ') is just as plausible as 'God caused $\sim p$ ' (Or 'God caused it to be the case that $\sim p$ '). That is, for any true contingent proposition $p$, citing God is just as good a causal explanation of $p$ as of $\sim p$.

This creates a principled problem for employing God in contrastive explanation. Statements of the form 'God explains why $p$ rather than $\sim p$ ' can never be true, because citing God can never account for the contrast between $p$ and $\sim p$. Ironically, then, it is God's omnipotence that makes Him explanatorily impotent. God's omnipotence entails that for any proposition $p$, God can equally easily make it to be that $p$ (rather than $\sim p$ ) and that $\sim p$ (rather than $p$ ), thereby explaining it, since, by $\mathrm{A}_{5}$, causal explanation is a variety of explanation. Therefore, for any proposition we might seek to explain, God could serve equally well to explain both it and its contradictory, and so God would never add any explanatory value to a theory. Therefore, by A1, we are not possibly licensed in admitting God into our ontology. 
I now turn to consider four objections to this argument.

First, it might be objected that even though appeal to God cannot figure in contrastive causal explanation, it can still figure in different forms of explanation.

One reply would be to embrace the thesis that all explanation is causal. But that is unnecessary. Even if $p$ can be explained non-causally whereas $\sim p$ cannot, it remains the case that $\sim p$ can be explained causally, since everything can be explained causally by appeal to God's doings. So for any proposition, some explanation of its negation by appeal to God would be available.

Second, it might be claimed that the argument commits a verificationist fallacy. It may show that we cannot establish whether God actually brought it about that $p$ or that $\sim p$. From this it does not follow, however, that there is no fact of the matter as to whether God brought it about that $p$ or that $\sim p$.

This objection is an ignoratio elenchi. The above argument is not supposed to show that God does not exist. Rather, it purports to show that there is not - or more accurately, could not - be reason to believe that He does. That is, the claim is that belief in the existence of God is epistemically unjustified. The argument does not impose a verificationist constraint on truth or reality, though it may impose a verificationist constraint on justification.

Third, if one grants $\mathrm{Al}_{1}-\mathrm{A}_{4}$, then the most obvious objection to the argument is that God may have reasons to cause $p$ rather than $\sim p$ and he brings about $p$ and so some statements of the form 'God explains $p$ rather than $\sim p$ ' can be true after all. That is, although God could cause anything, it does not follow that He would. 
God may have good reasons for preferring the obtaining of $p$ over the obtaining of $\sim p$, and act on those reasons. Another way of putting the point is this: If we are asked 'Why $p$ rather than $\sim p$ ?', it seems perfectly proper to answer: 'Because God had preferred $p$ to $\sim p$ and consequently chose to bring about $p$.'

However, in the proposed explanations, the appeal to God does no explanatory work. Instead, the appeal to the reasons attributed to God (and his choosing to act on them) does the explanatory work and that appeal just presupposes God's existence and so gives us no reason to introduce God into our ontology.

In reply, it might be said that the reasons God has for preferring $p$ to $\sim p$ do not all by themselves cause $p$ to be true rather than $\sim p$. So God's existence is surely an essential component of the causal explanation of why $p$ is true rather than $\sim p$. The reasons God has for bringing about $p$ rather than $\sim p$ do not do any explanatory work on their own; they help explain something $p$ only insofar as God has these reasons and brings about $p$ for those reasons. God's existence is an essential constituent in this explanation. Insofar as God's acting for reason $R$ is the result of an inference to the best explanation, this appeal does not seem so much to presuppose God's existence as to provide grounds for positing God's existence.

However, we must distinguish between the 'what' component of a causal explanation and the 'why' component. In the explanation in question, God is the answer to the question 'What caused p?', while the reasons attributed to God (and his choosing to act on them) are the answer to the question 'Why did God cause $p$ 
rather than $\sim p$ ?" So, since explanations are answers to why questions, it is the reasons (and God's acting on them) that do all the explanatory work. That is, what explains the fact that $p$ rather than $\sim p$ is the fact that God has the reasons He does (and chooses to act on them). But that explanation already presupposes that there is a God. What we are still missing is an explanatory context in which God might be introduced into our ontology in the first place. If we are asked 'Why $p$ rather than $\sim p$ ?', it is no more acceptable to answer: 'Because God preferred $p$ to $\sim p$ and consequently chose to bring about p' than it would be to identify Jane's husband as her murderer on the grounds that Jane's husband preferred Jane dead rather than alive and consequently chose to murder Jane unless we already have an explanatory context in which Jane's husband is included in our ontology in the first place.

‘Because Jane’s husband preferred Jane dead and consequently chose to murder her' has no explanatory power in respect of Jane's death unless it is already justifiably believed that Jane has a husband.

Or to put it another way: when astronomers infer the existence of a planet from a telltale wobble in the star it orbits, it would indeed be bizarre to challenge the explanation on the grounds that it is certain of the planets properties (its mass, orbital path, distance from the star) that do the explanatory work, while the existence of the planet is presupposed - consequently, the proffered explanation gives us no reason to introduce the planet into our ontology. ${ }^{8}$ But that is because we already have planets in our ontology and have observed their effects. We

\footnotetext{
${ }^{8}$ This is the chief method by which astronomers discover exoplanets.
} 
already know planets exist. We do not already know God exists. To be a candidate for a cause we must already believe in entities of the relevant sort.

A fourth objection arises in connection with the modified version of A5. Given this restriction on God's omnipotence, the following problem arises. Many theists seek to include God in their ontology on the ground that He explains necessary truths. Leibniz, for example, argued that, since mathematical truths were necessary and eternal, they required a necessary and eternal truthmaker, viz. God's Ideas. Independent of the plausibility of such an argument, it is not ruled out by my argument when we account for the proper restrictions on Divine omnipotence. Given the possible need for explaining necessary truths, therefore, the argument fails.

My reply is twofold. First, many theists seek to introduce God on the basis of contingent considerations alone. Second, it is impossible for an agent (even an omnipotent agent) to bring about a necessary state of affairs (e.g., that all cubes are shaped) or make necessary truths necessary. It is possible for an agent, $a$, to make a necessary truth, $p$, necessary, only if possibly, (1) $a$ brings about $p$ and (2) if $a$ had not acted, then $p$ would have been false. Because a necessary truth is necessary whether or not anyone acts, (2) is false. Therefore, it is impossible for an agent to make a necessary truth necessary.

IV

I conclude that appeal to God is explanatorily impotent, and necessarily so, given 
the contrastive structure of explanation. This means that there could be no grounds on which to introduce God into our ontology. This argument neutralizes all a posteriori theistic arguments from the get-go: none can, in principle, license belief in God. ${ }^{9}$

References

Lewis, D. 1986. 'Causal explanation'. In his Philosophical Papers, Volume 2, Oxford: Oxford University Press.

Lipton, P. 1990. 'Contrastive explanation'. In D. Knowles (ed.), Explanation and its Limits, Cambridge: Cambridge University Press.

Lipton, P. 2001. 'What good is an explanation?'. In G. Hon \& S. Rakover (eds.), Explanation, Springer Netherlands.

Russell, B. 1997. 'Is there a God?'. In The Collected Papers of Bertrand Russell, Volume 11: Last Philosophical Testament, ed. J. G. Slater and P. Köllner, London: Routledge. 
